\title{
A PRÁTICA PEDAGÓGICA NO ENSINO SUPERIOR: PLANEJAMENTO, INTERDISCIPLINARIDADE E METODOLOGIAS ATIVAS
}

\section{PEDAGOGICAL PRACTICE IN HIGHER EDUCATION: PLANNING, INTERDISCIPLINARITY AND ACTIVE METHODOLOGIES}

Lívia Brisolla ${ }^{1}$

\begin{abstract}
Resumo
O presente trabalho é um estudo de revisão de literatura que versa sobre a necessidade de um redirecionamento da prática pedagógica, no sentido de romper com práticas pedagógicas tradicionais que resistem em fazer parte do ensino superior. Diante desse desafio, objetiva-se discutir a relevância de uma prática pedagógica comprometida com a práxis social, fundamentada em três pressupostos basilares: planejamento, interdisciplinaridade e metodologias ativas. Primeiramente, discute-se a concepção de prática pedagógica e apresentam-se suas perspectivas teórico-epistemológicas. Em seguida, relacionam-se esses pressupostos como elementos imprescindíveis para a mudança de postura docente frente ao processo de ensino-aprendizagem. Concluindo, compreende-se que as práticas pedagógicas emergem da práxis e, portanto, operam a partir da relação crítica e reflexiva que se estabelece entre os sujeitos, as intencionalidades e as formas de organizar e planejar, interdisciplinarmente, os conteúdos por meio das metodológicas ativas. Constata-se, assim, que a mudança da prática pedagógica se efetiva no trabalho coletivo consciente, intencional e integrado.
\end{abstract}

Palavras-chave: Prática Pedagógica; Interdisciplinaridade; Planejamento; Metodologias ativas.

\begin{abstract}
The present work is a literature review study about the need for a redirection of pedagogical practice, in the sense of breaking with traditional pedagogical practices that resist to do part of higher education. Facing this challenge, the objective is to discuss the relevance of a pedagogical practice committed to social praxis, based on three basic assumptions: planning, interdisciplinarity and active methodologies. First, the conception of pedagogical practice is discussed and its theoretical-epistemological perspectives are presented. Then, these assumptions are related as essential elements for the change of teaching position in relation to the teaching-learning process. Concluding, it is understood that pedagogical practices emerge from praxis and, therefore, operate from the critical and reflexive relationship established between the subjects, the intentionalities and the ways of organizing and planning,
\end{abstract}

${ }^{1}$ Doutora em Educação, Faculdade Araguaia. E-mail: liviabrisolla@ gmail.com

Revista Devir Educação, Lavras, vol.4, n.1, p.77-92 jan./jun., 2020. 
interdisciplinarily, the contents through active methodological. Thus, it is verified that the change in pedagogical practice takes place in conscious, intentional and integrated collective work.

Keywords: Pedagogical Practice; Interdisciplinarity; Planning; Active Methodologies.

\section{Introdução}

A sociedade contemporânea, marcada pelo avanço veloz e contínuo das tecnologias de informação e comunicação, configura um cenário impactante que almeja transformações teórico-práticas e político-sociais no âmbito da educação. Novos desafios se fazem presente frente às novas exigências das práticas pedagógicas no ensino superior e impulsionam os docentes a (re)pensarem e ampliarem sua consciência sobre a própria prática pedagógica em sala de aula. É um processo de mudança de postura que somente ocorre por intermédio de vivências e experiências que proporcionem a (re)estruturação e a incorporação de novos conceitos, práticas e comportamentos. Neste contexto, defende-se a mudança de postura docente, a partir de uma prática pedagógica inovadora, interdisciplinar e crítica, de forma que se torne sujeito autônomo. Contudo, esse é um dos grandes desafios da prática pedagógica.

Não se pode desconsiderar que, nos últimos anos, os temas ligados à prática pedagógica têm sido alvo de profundas discussões e preocupações por intelectuais de diversas áreas (CALDEIRA; ZAIDAN, 2013; FRANCO, 2012; VEIGA, 1989) e, também, por várias instituições do ensino superior. Há uma preocupação com uma prática pedagógica que procure transcender o viés da reprodução para alcançar um processo de produção de conhecimento, voltado para a reflexão e intervenção dos problemas. O docente, como agente norteador do processo de ensino-aprendizagem, quando busca novas metodologias e formas de organizar o conhecimento para construir e colaborar com a edificação de um saber mais aberto e conectado com a realidade social, transcende dinâmicas massificadas. Isso ocorre ao ressaltar que sua prática pedagógica em sala de aula tem papel vital no desenvolvimento intelectual dos seus discentes.

Diante disso, o interesse pelo tema advém da atuação como docente no ensino superior, que constantemente se depara com os desafios da prática pedagógica. Percebe-se certa resistência por parte de docentes e até discentes para que as mudanças aconteçam. Alguns 
questionamentos direcionaram o estudo, como: O que são práticas pedagógicas? Quais as suas perspectivas? Que mudança de postura se espera do docente e do discente diante das novas exigências? Quais os pressupostos essenciais para a prática pedagógica no ensino superior?

Tais questionamentos conduzem à reflexão sobre alguns temas imbricados à prática pedagógica. O texto foi organizado em três momentos: primeiramente, abordam-se as concepções e perspectivas teórico-epistemológicas do termo prática pedagógica. Em seguida, defende-se a prática de planejamento como pressuposto basilar para pensar as intencionalidades e a prática pedagógica docente comprometida com a práxis social transformadora. Logo depois, caracterizam-se a interdisciplinaridade e as metodologias ativas como possíveis caminhos para um redimensionamento das práticas pedagógicas. Por fim, relacionam-se os três pressupostos: planejamento, interdisciplinaridade e metodologias ativas frente aos desafios de um processo de ensino-aprendizagem como condição importante para uma efetiva prática pedagógica transformadora.

\section{Prática pedagógica: concepções e perspectivas teórico-epistemológicas}

As práticas pedagógicas são objeto de estudo fundamental no ensino superior e, sob diversos aspectos, podem trilhar diferentes concepções. Por isso, neste estudo, aborda-se a concepção proposta pela pesquisadora Maria Amélia Santoro Franco (2012, p. 152), que concebe as práticas pedagógicas como "práticas sociais exercidas com a finalidade de concretizar processos pedagógicos”. Em sentido mais amplo, está relacionada ao contexto social, político e histórico de uma dada realidade. Parte-se, deste modo, da visão da totalidade, que envolve questões epistemológicas, sociais e históricas, um universo complexo e multifatorial. Sua estrutura baseia-se em decisões, princípios, ideologias e estratégias que somente podem ser percebidos no âmbito da totalidade (FRANCO, 2012). É uma concepção de prática pedagógica que transcende a sala de aula e as questões metodológicas em direção a uma prática social intencional.

A prática pedagógica refere-se ao fazer pedagógico, não somente ao momento de execução - a aula, mas, sobretudo, ao processo de planejamento e avaliação. Por essa linha de raciocínio, relaciona-se com as atividades didáticas, abrangendo o cotidiano do trabalho docente em seus processos de ensino-aprendizagem. A prática pedagógica é "uma prática social orientada por objetivos, finalidades e conhecimentos e inserida no contexto da prática social. A

Revista Devir Educação, Lavras, vol.4, n.1, p.77-92 jan./jun., 2020. 
prática pedagógica é uma dimensão da prática social” (VEIGA, 1989, p. 16). Tal processo requer ponderar o trabalho docente em seu processo diário, o que exige considerá-lo sob duas dimensões: da práxis e da prática.

A práxis para a filosofia marxista é elucidada como relação dialética entre homem e natureza, na qual o homem, ao transformar a natureza com seu trabalho, transforma-se a si mesmo. A práxis é a ação do homem sobre a matéria que resulta em transformação, atividade material, transformadora e adequada a fins (VÁZQUEZ, 2007). Isso significa que a prática pedagógica intencional é uma práxis social embasada por objetivos, intencionalidades, finalidades e saberes, de modo que articule os conteúdos com o contexto social e histórico na (re)construção da própria realidade e do processo emancipatório dos indivíduos. Já a prática possui uma dimensão prático-utilitária, isto é, o ser humano viabiliza a resolução dos problemas, utilizando-se de conhecimentos técnicos em ações cotidianas do dia a dia, ou seja, desvinculada da teoria.

A expressão prática pedagógica é composta pela soma do termo prática, entendida como capacidade de ação do homem, com o termo pedagógico, que indica as ações praticadas pelo docente no contexto educativo. Ambos os termos se unem e representam uma dimensão social da práxis, porque se realizam por intenções conscientes, articuladas entre si, numa relação teoria e prática, em direção à transformação e às mudanças qualitativas. Isso se dá pela veiculação e produção de conhecimentos ou pelo desenvolvimento de hábitos, atitudes e habilidades pelos alunos.

No que concerne à definição de prática pedagógica, Veiga (1989) apresenta duas vertentes, uma repetitiva e outra reflexiva. A prática repetitiva, segundo a autora, é caracterizada por uma lei estabelecida a priori. Apesar da consciência de estar presente, ela acontece de forma instrumental, mecânica e burocrática. Já a prática pedagógica reflexiva esclarece a indissociabilidade entre teoria e prática e viabiliza a prática social como ponto de partida. Sendo um processo que demanda constante reflexão e ação, é uma postura democrática e participativa que reverbera em ações coletivas e dialógicas. A reflexão, na perspectiva da criticidade, conduz à autonomia, que é a capacidade e a liberdade de (re)construir o conhecimento, o ponto de equilíbrio entre as vertentes de autoridade e de liberdade no processo educativo (FREIRE, 1996).

De acordo com as dimensões teórico-epistemológicas, a prática pedagógica pode assumir as seguintes perspectivas: positivista, interpretativa e histórico-crítica ou dialética. A 


\section{OO DEVIR EDUCAÇÃO}

ISSN: 2526-849X

perspectiva positivista destaca uma única realidade que pode ser fragmentada, ou seja, dividida em partes que somente aceitam o conhecimento embasado na realidade tal como a captamos por meio dos sentidos. Deste modo, a prática pedagógica "é o resultado da aplicação de conhecimentos teóricos, extraídos de diferentes disciplinas científicas na resolução de problemas, percorrendo um caminho no sentido da ideia à ação, dos princípios teóricos à prática" (CALDEIRA; ZAIDAN, 2013, p. 16).

A perspectiva interpretativa evidencia que a realidade é construída socialmente pelo homem, ao dar significado aos objetos, às circunstâncias e às experiências vividas. Neste sentido, o ser humano é o criador do conhecimento e da realidade e, neste contexto, impõe-se o caráter intencional da atividade humana. Caldeira e Zaidan (2013, p. 17), a esse respeito, aludem que a prática pedagógica "é o resultado de um processo que tem o seu início na própria prática, informada tanto pela teoria como pela situação particular vivenciada pelo ator”.

Por fim, a perspectiva histórico-crítica ou dialética apreende a realidade como totalidade concreta, como um todo que possui sua própria estrutura. Destarte, os acontecimentos fazem parte de uma totalidade concreta, mesmo que não os se perceba claramente. Isso significa que a realidade não é cristalina e, por isso, para entendê-la, é importante apreendê-la por dentro, em seus processos e múltiplas relações. Com isso, não é possível conceber a totalidade como um todo finalizado que determina as partes, pois a sua própria determinação pertence à gênese e ao desenvolvimento da totalidade (CALDEIRA; ZAIDAN, 2013). Por esse motivo, os teóricos chamam atenção para se questionar sobre a origem e o processo de desenvolvimento da totalidade, já que é essa a condição para que ela se transforme em totalidade histórica.

É por essa ótica que teoria e prática são indissociáveis para que a consciência da práxis se estabeleça. Como sublinhado por Vázquez (2007, p. 262), a práxis é “atividade teórico-prática; isto é, tem um lado ideal, teórico, e um lado material, propriamente prático, com a particularidade de que só artificialmente, por um processo de abstração, podemos separar, isolar um do outro". Decorre daí uma prática pedagógica como uma prática social que permeia diferentes espaços e tempos, pela relação entre docente e discente diante dos elementos, situações e experiências que circunscrevem esse universo complexo. Caldeira e Zaidan (2013) expõem que:

[...] a prática pedagógica é, ao mesmo tempo, a expressão e a fonte do saber docente, e do desenvolvimento da teoria pedagógica. Assim, ao mesmo tempo em que o professor age segundo suas experiências e aprendizagens, ele cria e enfrenta desafios cotidianos (pequenos e grandes) e, com base neles, constrói

Revista Devir Educação, Lavras, vol.4, n.1, p.77-92 jan./jun., 2020. 


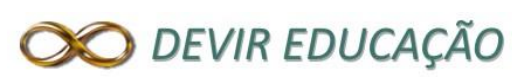

ISSN: 2526-849X

conhecimentos e saberes, num processo contínuo de fazer e refazer. (CALDEIRA; ZAIDAN, 2013, p. 21).

Não dá para pensar a prática pedagógica descolada da teoria e dos saberes docentes, porque está circunscrita à ação intencional do docente em direção ao processo de ensinoaprendizagem. A prática pedagógica é um processo que expressa reflexão e intervenção docente, sob as bases teórico-práticas que se iniciam desde a pesquisa inicial para pensar a organização do trabalho pedagógico, incluindo a ação de planejar. Assim, as práticas pedagógicas "se realizam para organizar/potencializar/interpretar as intencionalidades de um projeto educativo [...] realizam-se como sustentáculos à prática docente, num diálogo contínuo entre os sujeitos e suas circunstâncias e não como armaduras à prática” (FRANCO, 2016, p. $63)$.

\section{Práxis pedagógica: planejamento e intencionalidade}

A práxis pedagógica pode ser compreendida como ação consciente e intencional que, imbuída de uma teoria, percebe e interpreta a realidade na mesma proporção em que busca transformá-la e, ao mesmo tempo, ser transformada. Neste sentido, não há práxis pedagógica ausente de uma teoria pedagógica. Franco (2016) chama atenção para a urgência de se convocar novamente a teoria pedagógica como construtora e interpretadora da práxis. Se, por um lado, verificam-se práticas pedagógicas no ensino superior puramente técnicas e desarticuladas das demandas sociais, o que obstrui a reflexão sobre a ação e as possíveis mudanças, por outro se percebem práticas pedagógicas essencialmente teóricas. A perspectiva é superar a racionalidade técnica, que pensa a teoria como momento de abstração, e a prática como situação do fazer.

Trata-se de pensar a práxis pedagógica na contramão da racionalidade técnica, já que esse modelo não compreende a educação como um compromisso político e social. A partir dessa concepção, promove-se uma práxis social fundamentada na racionalidade crítica, que preza pela indissociabilidade entre teoria e prática, e aponta para uma ação consciente, orientada por uma dada teoria que resulta na práxis. É um processo contínuo de reflexão da práxis educativa consciente, dado que é pensando criticamente sobre a prática de hoje e de ontem, que pode se transformar na próxima prática, como apregoa Paulo Freire (1996).

Revista Devir Educação, Lavras, vol.4, n.1, p.77-92 jan./jun., 2020. 
A atividade docente é sempre práxis, uma vez que envolve: uma intencionalidade que dirige e dá sentido à ação; o conhecimento do objeto que quer se transformar na direção de sua intencionalidade, e a intervenção planejada e científica sobre o objeto com vistas à transformação da realidade social (PIMENTA; ANASTASIOU, 2014). Em face disso, toda atividade docente deve ser planejada e contextualizada, de modo que articule os conteúdos interdisciplinarmente com o contexto social e histórico.

A práxis é "atividade material, transformadora e adequada a fins" (VÁZQUEZ, 2007, p. 237). Por isso, é primordial que a prática pedagógica seja desenvolvida como práxis social, ou seja, voltada para uma ação consciente e transformadora de uma dada realidade. O ponto de partida é a prática social, isto é, a realidade, em seu aspecto: social, político, econômico, cultural, histórico e educacional. Tal processo pressupõe reflexão crítica da realidade, problematizando e contextualizando o educacional e o social. Nesta perspectiva, é crucial que o professor compreenda os vínculos da sua prática com a prática social global (SAVIANI, 2003). A “prática pedagógica é uma dimensão da prática social que pressupõe a relação teoriaprática, e é essencialmente nosso dever, como educadores, a busca de condições necessárias à sua realização" (VEIGA, 1989, p. 16).

A práxis pedagógica no processo de ensino-aprendizagem é objeto de reflexão no ensino superior. O conhecimento e a experiência desenvolvidos pelo docente durante a sua trajetória profissional contribuem, aliados à dimensão crítica, para uma práxis interdisciplinar. No entanto, esse é um processo desafiador de mudanças: de postura docente, das formas de organizar o trabalho pedagógico e na maneira de desenvolver suas ações didático-pedagógicas. Isso implica, primeiramente, uma leitura crítica da realidade em seu aspecto social, político, econômico, cultural e educacional, como fundamento para que o docente defina os objetivos que pretende alcançar com seus discentes. O docente, a partir daí, será capaz de contextualizar e questionar a finalidade social dos conteúdos e das intencionalidades didático-pedagógicas da atividade docente (SAVIANI, 2003). Em segundo, sua prática pedagógica deve partir de uma visão de totalidade do processo de ensino-aprendizagem, que engloba tanto a ação de ensinar quanto de aprender. Cabe assinalar que a visão de totalidade remete tanto ao currículo - de forma que os conceitos sejam apreendidos como sistema de relações de uma totalidade concreta que se pretende explicar, ou seja, pela via de um currículo integrado - quanto dos processos pedagógicos, de maneira que transcenda as formas tradicionais que valorizam a dimensão técnica do ato de planejar desarticulada.

Revista Devir Educação, Lavras, vol.4, n.1, p.77-92 jan./jun., 2020. 
Nessa dinâmica, relaciona-se a urgência de um contínuo processo de integração, reflexão e participação dos discentes nas decisões coletivas. A prática pedagógica está sujeita a múltiplas situações não previstas que ecoam sobre os discentes e os docentes e os convidam a repensar os caminhos. É crucial que o projeto político-pedagógico de qualquer curso de graduação, por exemplo, seja construído pelo coletivo docente do curso sob os pilares da flexibilidade, da contextualização e da interdisciplinaridade. Inclui, ainda nesse processo dinâmico e dialógico, articular teoria/prática em prol de um olhar sob a totalidade do processo de ensino-aprendizagem.

A prática pedagógica não pode ser uma atividade desenvolvida sem planejamento e intencionalidade, mesmo que o docente tenha profundo conhecimento de sua disciplina. Ademais, a prática docente é constituída das dimensões pedagógicas e político-sociais e do compromisso docente com desenvolvimento do seu trabalho. Aqui se coloca a questão do planejamento como elemento valoroso para o desenvolvimento do trabalho docente, enquanto ação pedagógica crítica e transformadora. Para Vasconcellos (1995), o planejamento deve ser entendido como um instrumento capaz de intervir em uma situação real para transformá-la.

O planejamento não pode ser percebido de maneira mecânica, desvinculado da realidade social. Envolve a reflexão-ação de planejar, definir os objetivos e contextualizar frente ao vasto universo de conhecimentos/disciplinas, realidade e saberes, sendo um processo dinâmico e contínuo que demanda empenho docente e reflexão crítica sobre a própria prática pedagógica. Nesse sentido, o planejamento corresponde ao conjunto organizado de intenções/ações que busca alcançar determinado objetivo. É um processo contínuo de tomada de decisão (VASCONCELLOS, 1995) constituído e inerente à prática pedagógica.

O problema é que os planejamentos elaborados por grande parte dos docentes se mostram de forma estratificada, sem a preocupação de se estabelecer uma relação entre os seus vários elementos. Os objetivos, por exemplo, são inseridos sem o docente ter a clareza do que pretende com determinada prática pedagógica, o que resulta num amontoado de objetivos confusos e desvinculados da realidade social. Além disso, ressoa-se aqui a denúncia feita por Pimenta e Anastasiou (2014, p. 113) de que "estamos acostumados a processos de planejamento, execução e avaliação das atividades de forma individualista e solitária". A resistência em incorporar outras metodologias e processos de planejamento coletivos reflete uma prática pedagógica permeada de problemas que jamais podem ser resolvidos à luz da improvisação.

Revista Devir Educação, Lavras, vol.4, n.1, p.77-92 jan./jun., 2020. 


\section{OO DEVIR EDUCAÇÃO}

ISSN: 2526-849X

Freitas (1995) assevera a volta do neotecnicismo no interior das práticas pedagógicas de muitos docentes, nas avaliações e no planejamento padronizado que por muitos anos se repetem. O neotecnicismo revela uma prática pedagógica ancorada no discurso ideológico de produtividade e racionalidade, que obscurece a dimensão política e pedagógica. Logo, o ato de planejar não se resume à ação mecânica de um trabalho burocrático, mas sim a um processo de reflexão crítico e intencional que visa integrar e transformar. É um processo que exige que se tenha clareza das intenções/ações e que deseja atingir um determinado objetivo. Portanto, é um processo constituído inerente a uma prática pedagógica compromissada com a qualidade do processo de ensino-aprendizagem, que inclui a prática de planejar coletivamente e individualmente. Entretanto, não basta que o docente planeje cuidadosamente seus projetos e atividades de forma coletiva e intencional se não for imbuído por uma dinâmica constante de reflexão crítica em prol da melhoria.

\section{Prática pedagógica: interdisciplinaridade e metodologias ativas}

As instituições de ensino superior têm discutido a questão da interdisciplinaridade e das metodologias ativas no sentido de ampliar o processo de ensino-aprendizagem em direção a uma formação emancipatória. Pensar tais questões impõe trazer a questão da participação e do diálogo entre docente, discente e a instituição de ensino superior, como também pensar o papel do discente frente a novas exigências profissionais e formativas da realidade político-social. Santomé (1998) salienta a relevância de se construir experiências curriculares na perspectiva da interdisciplinaridade e integração.

Para Freitas (1995, p. 91), a interdisciplinaridade é entendida como a "interpenetração de método e conteúdo entre as disciplinas que se dispõem a trabalhar conjuntamente um determinado objeto de estudo". A interdisciplinaridade é caracterizada pela integração, que garante maior comunicação entre as disciplinas e, por conseguinte, cria espaço para o fortalecimento da interdisciplinaridade.

A integração dá ênfase à unidade de que é preciso existir entre as diferentes disciplinas. Existem quatro formas de integrar um currículo: integração correlacionando várias disciplinas; integração por meio de ideias ou temas; integração em torno de uma questão da vida e integração a partir de temas e pesquisas decididos pelos discentes (SANTOMÉ, 1998). Integrar não significa abandonar as disciplinas, mas integrá-las de modo que se crie maior diálogo e

Revista Devir Educação, Lavras, vol.4, n.1, p.77-92 jan./jun., 2020. 


\section{OO DEVIR EDUCAÇÃO}

ISSN: 2526-849X

trânsito entre as disciplinas. A integração pressupõe a aproximação dialógica entre o corpo docente, os discentes e a instituição de ensino, para que seja possível promover modificações das "práticas participativas e colaborativas em que os docentes sejam protagonistas dos processos de mudança. A ideia é introduzir nos cursos espaços de reflexão conjunta, trocas de experiência, formas de negociação e tomada de decisões coletivas" (LIBÂNEO, 2003, p. 2). A parceria docente e discente sustenta uma relação horizontal mediada pelo diálogo e pela coletividade. Essa nova postura solicita uma visão de totalidade dos processos pedagógicos, dos conteúdos e do currículo, exigindo, assim, um projeto coletivo capaz de estabelecer um diálogo marcado pela integração entre as disciplinas. A interdisciplinaridade busca a construção de um sujeito coletivo que emerge do trabalho em equipe, a partir da parceria e da integração das partes em relação ao todo em direção à compreensão do mundo.

A integração das disciplinas postula uma forma dinâmica e contínua de perceber, interagir e intervir os saberes que se realizam na prática pedagógica. Em função disso, procurase nas metodologias ativas um caminho para pensar estratégias de ensino nos quais os discentes assumem um comportamento mais dinâmico e participativo, realizam atividades que estabelecem relações entre o contexto, as estratégias cognitivas e o processo de construção de conhecimento (VALENTE; ALMEIDA; GERALDINE, 2017).

Assim, as metodologias ativas realçam a participação ativa do discente no processo de ensino-aprendizagem. O discente deixe de ser espectador passivo para se tornar sujeito ativo, retirando, assim, o docente do centro do processo como única fonte de saber. As metodologias ativas "têm o potencial de despertar a curiosidade, à medida que os alunos se inserem na teorização e trazem elementos novos, ainda não considerados nas aulas ou na própria perspectiva do professor" (BERBEL, 2011, p. 28). Trata-se de um processo de ensinoaprendizagem mais democrático e menos hierárquico no qual a relação entre docente e discente é redefinida.

As mudanças no campo da educação caminham em direção as práticas pedagógicas inovadoras e interdisciplinares no ensino superior, no sentido de promover rupturas com metodologias de ensino como processo de mera transmissão de conhecimento de um indivíduo que sabe a outro que não sabe, pois, como anuncia Paulo Freire (1996), ensinar tem que ser um ato prazeroso e despertar no discente o desejo de aprender. Neste desafio, apontam-se como alternativas as metodologias ativas, que são processos interativos de conhecimentos, análises, pesquisas e decisões individuais e coletivas, com o objetivo de pensar soluções para um

Revista Devir Educação, Lavras, vol.4, n.1, p.77-92 jan./jun., 2020. 


\section{OO DEVIR EDUCAÇÃO}

ISSN: 2526-849X

determinado problema, em meio a um contexto em que o papel do docente é facilitar e orientar para que os discentes alcancem os objetivos estabelecidos (BERBEL, 2011).

As metodologias ativas exigem mudança de postura acadêmica, compromisso, responsabilidade e autonomia, visto que são condescendentes com a concepção críticoreflexiva. No entanto, adotar uma metodologia ativa ainda é um desafio, pois envolve relações de resistências, falta de conhecimento e maturidade discente. Diante disto, é necessário que o docente compreenda as metodologias ativas na perspectiva da interdisciplinaridade e as incorpore pedagogicamente na prática pedagógica. Trata-se de analisar criticamente as metodologias ativas intencionais e transformadoras, pois não basta inserir novas metodologias sem que o docente compreenda suas potencialidades articuladas aos conteúdos e objetivos desejáveis.

De acordo com Berbel (2011), são muitas as possibilidades de metodologias ativas, tais como: o estudo de caso; o método de projetos e; a aprendizagem baseada em problemas. No estudo de caso, os discentes se organizam em grupos para resolver problemas associados com a atividade profissional futura, tendo o apoio docente. Neste processo, os discentes discutem os caminhos e as formas de se elucidar a problemática proposta. A cada encontro, o docente interage, reflete e avalia junto ao grupo o progresso. O estudo de caso é "bastante utilizado em cursos de Direito, Administração, Medicina entre outros. Com o estudo de caso o aluno é levado à análise de problemas e tomada de decisões” (BERBEL, 2011, p. 30).

No método de projeto, os discentes desenvolvem um projeto sob a orientação docente. As discussões são realizadas a cada encontro e são significativas porque condizem com a vida profissional. Ao longo do processo, os envolvidos tomam decisão acerca do desenvolvimento de todos os detalhes do projeto. É uma modalidade que "pode associar atividades de ensino, pesquisa e extensão" (BERBEL, 2011, p. 31).

Outra modalidade importante no campo das metodologias ativas é a aprendizagem baseada em problemas, também conhecida como PBL (Problem Based Learning). Trata-se da utilização de situações problemas com o objetivo de que o conteúdo seja discutido e o solucionado pelos estudantes. A aprendizagem baseada em problemas vem sendo desenvolvida em diferentes cursos de graduação no Brasil, sobretudo, nos cursos de medicina (BERBEL, 2011).

Ambas as metodologias ativas, projeto e problema conduzem às práticas pedagógicas inovadoras e interdisciplinares que, consequentemente, concebem um processo de ensino- 


\section{ODEVIR EDUCAÇÃO}

ISSN: 2526-849X

aprendizagem dinâmico e com conceitos e conhecimentos integrados. Com efeito, promovem experiências reais e/ou simuladas em prol de solucionar com êxito os desafios advindos das atividades essenciais da prática social em diferentes contextos (BERBEL, 2011). Permeadas por um processo de reflexão, crítica, desafios e descobertas, as metodologias ativas aproximam o discente da realidade e dos problemas da sociedade.

A interdisciplinaridade expande as possibilidades de uma formação mais crítica e conectada com as necessidades da comunidade. Porém, um dos grandes desafios docentes é transcender práticas repetitivas e tradicionais que pouco desperta o interesse e a curiosidade dos discentes. Libâneo (2003) atesta que o grande problema está na prática do ensino tradicional, e não diretamente no docente. Isso demonstra que o docente anseia por aprender em diferentes lentes de aumento, saindo da sua zona de conforto e conquistando novos conhecimentos, representando comprometimento de ambos. $\mathrm{O}$ autor designa algumas atribuições à prática docente e ao processo de aprendizagem:

1. O foco, o nuclear da prática docente é a aprendizagem do aluno, resultante da sua própria atividade intelectual e prática realizada em parceria com os professores e colegas; 2 . A sala de aula é um espaço de construção conjunta do conhecimento; 3. A aprendizagem está relacionada com a atividade de pesquisa tanto do aluno quanto do professor; 4. A sala de aula é todo espaço em que os alunos podem aprender; 5. Toda aprendizagem precisa ser significativa; 6. A sala de aula implica uma aproximação entre a teoria e a prática; 7. A aprendizagem universitária está associada ao aprender a pensar e ao aprender a aprender. (LIBÂNEO, 2003, p. 8).

A prática pedagógica introduz critérios e procedimentos constantes do aprimoramento dos conhecimentos absorvidos durante toda a trajetória curricular, capazes de envolver tanto o docente quanto o discente no processo de ensino-aprendizagem, inclusive culminando em ações inovadoras de avaliação.

Estudos demonstram que parte dos docentes do ensino superior em curso de bacharelado detém o conhecimento específico, todavia, desconhece metodologias aplicáveis à educação superior. Em vista disto, observa-se que muitas práticas pedagógicas que enfatizam a repetição e a memorização são insuficientes para atender os desafios e as expectativas das diferentes áreas do conhecimento.

Revista Devir Educação, Lavras, vol.4, n.1, p.77-92 jan./jun., 2020. 


\section{OO DEVIR EDUCAÇÃO}

ISSN: 2526-849X

Na obra A prática pedagógica do bacharel professor da área de comunicação social, Renata Carvalho (2013), ao analisar as práticas pedagógicas docentes, identifica que os problemas são: falta de formação específica para a docência; inadequação dos métodos aos conteúdos; avaliação centrada em instrumentos; resistência discente ao ensino sem diálogo e separação entre teoria e prática. Por essa pesquisa, verifica-se que o movimento em favor da prática pedagógica como práxis social no contexto do ensino superior, ao qual se defende, fica prejudicado pela existência da divisão do conhecimento em disciplinas.

A prática pedagógica com currículos engessados e distanciados da práxis social, na visão de Franco (2016),

tem produzido enorme distanciamento das esferas pedagógicas e educativas, dando a ilusão de desarticulação entre teoria e prática, mas, na realidade, pode ser uma bem montada estratégia para que os processos formativos se distanciem da esfera reflexiva e, assim, se tornarem mais rentáveis. (FRANCO, 2016, p. 65).

Por isso a necessidade de pensar um currículo interdisciplinar no ensino superior rumo a mudanças das práticas pedagógicas a partir do existente, criando ideias e desenvolvendo metodologias ativas, as quais o discente tenha voz e assuma o compromisso com o aprender. É um processo de ensino-aprendizagem baseado na relação dialógica e participativa entre os discentes/discentes, discentes/docentes e docentes/docentes da instituição. A interdisciplinaridade requer a dinamicidade de uma prática pedagógica dialógica, problematizadora e investigativa, que não prescinda da análise crítico-reflexiva do contexto histórico sobre o qual a educação superior esteve alicerçada ao longo de sua evolução.

\section{Considerações finais}

É tarefa do processo de mudanças das práticas pedagógicas a integração enquanto ação que "exige dos professores, além de uma vontade de praticar a interdisciplinaridade, uma atitude de investigação, de colaboração e de trabalho em equipe, com metas comuns a serem alcançadas" (SANTOMÉ, 1998, p. 29). A prática pedagógica implica um trabalho interdisciplinar desenvolvido pelo coletivo, a partir de um processo de planejamento para que esta não se torne intuitiva, mas tenha objetivos concretos. Sabe-se que a prática pedagógica é uma prática social imbuída de intencionalidades e, por isso, roga pela definição de objetivos claros, com base no comprometimento do coletivo e na reflexão da realidade.

Revista Devir Educação, Lavras, vol.4, n.1, p.77-92 jan./jun., 2020. 
Nesse quadro, a prática pedagógica significa o conjunto de ações docentes, orientadas por uma intencionalidade transformadora na/para a práxis social, que possibilite melhorar a qualidade do processo de ensino-aprendizagem mediante a conscientização e o movimento contínuo de análise crítica da própria prática pedagógica. Essa visão baseada nas ações docentes reafirma a atuação conjunta entre a instituição de ensino superior, os docentes e os discentes, para que haja mudança na prática pedagógica.

Com esse propósito, sabe-se que toda prática pedagógica é intencional, carregada de teorias e valores que impõem muitos desafios ao docente. Estes convergem na ambivalência, já que a prática pedagógica pode ser tanto espaços de negociação, resistência e transformação, quanto espaços de dominação e reprodução ideológica. Assim, os desafios e contradições devem ser enfrentados pelos docentes e discentes, a fim de transformar a prática pedagógica em espaços de enfretamentos, diálogo e consciência crítica para a efetiva superação da prática para a práxis. Propõe-se aqui uma prática pedagógica comprometida com a práxis social e, por esse viés, acredita-se que as metodologias ativas são um caminho a ser trilhado para um redimensionamento da prática pedagógica.

Para que atividades pedagógicas possam ser consideradas práxis, é vital que os docentes compreendam os projetos pedagógicos dos cursos e, inclusive, participem da sua elaboração e de seu aprimoramento e tenham consciência, mediante a reflexão crítica, da formação que se pretende desenvolver com os discentes. É um trabalho de reflexão-ação-reflexão desenvolvido por meio da colaboração e cooperação, ou seja, a prática pedagógica se realiza no trabalho coletivo.

Com base nessas prerrogativas, infere-se que as metodologias ativas são uma possibilidade que necessita ser compreendida pelo docente e introduzida pedagogicamente na prática pedagógica. Todavia, se por um lado as metodologias ativas podem embasar-se em várias bases epistemológicas, como metodologias, tal como o construtivismo, por outro, muitas vezes são utilizadas como técnicas isoladas e desarticuladas pedagogicamente, fragmentando o processo de ensino-aprendizagem.

Nesse emaranho de complexidade e desafios, ressalta-se a relevância de três pressupostos indispensáveis para um redimensionamento da prática pedagógica: a prática de planejamento intencional; a interdisciplinaridade como elemento que transcende a visão fragmentada do conhecimento, do currículo e da organização do trabalho pedagógico e das metodologias ativas como meio para se introduzir projetos e formas diversidades de ensinar e

Revista Devir Educação, Lavras, vol.4, n.1, p.77-92 jan./jun., 2020. 
aprender. Esses pressupostos se completam a partir de cada especificidade. Não obstante, configuram os fundamentos para que se efetivem as reais mudanças nas práticas pedagógicas. Aceitar essa mudança indica que o docente aceita o desafio de (re)pensar sua prática pedagógica, movido pelo sentimento de renovação e de promoção da transformação com a implementação de metodologias e práticas interdisciplinares devidamente planejadas a partir da prática social.

Diante do exposto é importante que, ao redimensionar a prática pedagógica, o docente perceba sua condição como ser histórico, que educa e ao mesmo é educado, que intervém e ao mesmo tempo sofre intervenção, numa dinâmica dialética com o mundo que o cerca. Assumir o planejamento, a interdisciplinaridade e as metodologias ativas como pressupostos orientadores da prática pedagógica não significa se render ao novo porque é diferente, mas assumir sua dimensão histórica, procurando romper com práticas pedagógicas tecnicistas de ensino-aprendizagem.

\section{Referências}

BERBEL, Neusi Aparecida Navas. As metodologias ativas e a promoção da autonomia de estudantes. Semina, Londrina, v. 32, n. 1, p. 25-40, jan./jun. 2011. Disponível em: <http://www.uel.br/revistas/uel/index.php/seminasoc/article/view/10326/0>. Acesso em: 20 jan. 2018.

CALDEIRA, Anna Maria Salgueiro; ZAIDAN, Samira. Práxis pedagógica: um desafio cotidiano. Paidéia, Belo Horizonte, n. 14, p. 15-32, jan./jun. 2013. Disponível em: < https://pdfs.semanticscholar.org/a2ba/e75b7c25fe3245b9e3712b43a2d83b576061.pdf>.

Acesso em: 12 fev. 2018.

CARVALHO, Renata Bittencourt. A prática pedagógica do bacharel professor da área de comunicação social. Rio de Janeiro: Bookmakers, 2013.

FRANCO, Maria Amélia Santoro. Pedagogia e prática docente. São Paulo: Cortez, 2012.

FRANCO, Maria Amélia Santoro. Relações do docente-bacharel do ensino superior com o saber didático-pedagógico: dissonâncias e rupturas entre saberes e práticas. Em Aberto, Brasília, v. 29, n. 97, p. 61-72, set./dez. 2016. Disponível em: < http://rbepold.inep.gov.br/index.php/emaberto/article/view/2950>. Acesso em: 10 fev. 2018.

FREIRE, Paulo. Pedagogia da autonomia: saberes necessários a prática educativa. São Paulo: Paz e Terra, 1996.

Revista Devir Educação, Lavras, vol.4, n.1, p.77-92 jan./jun., 2020. 
FREITAS, Luiz Carlos. Crítica da organização do trabalho pedagógico e da didática. Campinas: Papirus, 1995.

LIBÂNEO, José Carlos. O ensino de graduação na universidade: a aula universitária. Goiânia: UCG, 2003.

PIMENTA, Selma Garrido; ANASTASIOU, Léa das Graças Camargos. Docência no ensino superior. São Paulo: Cortez, 2014.

SANTOMÉ, Jurjo Torres. Globalização e interdisciplinaridade: o currículo integrado. Porto Alegre: Editora Artes Médicas Sul Ltda, 1998.

SAVIANI, Dermeval. Escola e democracia. Campinas: Autores Associados, 2003.

VALENTE, José Armando; ALMEIDA, Maria Elizabeth; GERALDINI, Alexandra. Metodologias Ativas: das concepções às práticas em distintos níveis de ensino. Revista Diálogo Educacional, Curitiba, v. 17, n. 52, p. 455-478, abr./jun, 2017. Disponível em: < https://periodicos.pucpr.br/index.php/dialogoeducacional/issue/view/908>. Acesso em: 20 fev. 2019.

VASCONCELlOS, Celso dos Santos. Planejamento: Plano de Ensino-Aprendizagem e Projeto Educativo - elementos metodológicos para elaboração e realização. São Paulo: Libertad, 1995.

VÁZQUEZ, Adolfo Sánchez. Filosofia da práxis. São Paulo: Expressão popular, 2007.

VEIGA, Ilma Passos Alencastro. A Prática Pedagógica do Professor de Didática. São Paulo: Papirus, 1989.

Recebido em: 30/09/2019.

Aprovado em: 05/12/2019.

Revista Devir Educação, Lavras, vol.4, n.1, p.77-92 jan./jun., 2020. 